\title{
Determinants of hypomagnesemia in patients with type 2 diabetes mellitus
}

\section{Steef Kurstjens', Jeroen H F de Baaij', Hacene Bouras', René J M Bindels', Cees J J Tack ${ }^{2}$ and Joost G J Hoenderop' ${ }^{1}$}

${ }^{1}$ Departments of Physiology and ${ }^{2}$ Internal Medicine, Radboud Institute for Molecular Life Sciences, Radboud University Medical Center, Nijmegen, The Netherlands
Correspondence should be addressed to J G J Hoenderop Email

joost.hoenderop@ radboudumc.nl

\begin{abstract}
Background: Hypomagnesemia (plasma magnesium $\left(\mathrm{Mg}^{2+}\right)$ concentration $<0.7 \mathrm{mmol} / \mathrm{L}$ ) has been described in patients with type 2 diabetes. Polypharmacy is inevitable when treating a complex disease such as type 2 diabetes and could explain disturbances in the plasma $\mathrm{Mg}^{2+}$ concentration. In this study, we aimed to establish the extent of hypomagnesemia in a cohort of type 2 diabetes patients and to identify the determinants of plasma $\mathrm{Mg}^{2+}$ levels. Methods: Patient data and samples of 395 type 2 diabetes patients were investigated. Plasma $\mathrm{Mg}^{2+}$ concentrations were measured using a spectrophotometric assay. Using Pearson correlation analyses, variables were correlated to plasma $\mathrm{Mg}^{2+}$ levels. After excluding confounding variables, all parameters correlating $(P<0.1)$ with plasma $\mathrm{Mg}^{2+}$ were included in a stepwise backward regression model.

Results: The mean plasma $\mathrm{Mg}^{2+}$ concentration in this cohort was $0.74 \pm 0.10 \mathrm{mmol} / \mathrm{L}$. In total, 121 patients $(30.6 \%)$ suffered from hypomagnesemia. Both plasma triglyceride $(r=-0.273, P<0.001)$ and actual glucose levels $(r=-0.231$, $P<0.001)$ negatively correlated with the plasma $\mathrm{Mg}^{2+}$ concentration. Patients using metformin $(n=251,62 \%)$, proton pump inhibitors $(n=179,45 \%)$ or $\beta$-adrenergic receptor agonists $(n=31,8 \%)$ displayed reduced plasma $\mathrm{Mg}^{2+}$ levels. Insulin use $(n=299,76 \%)$ positively correlated with plasma $\mathrm{Mg}^{2+}$ levels. The model predicted $\left(R^{2}\right) 20 \%$ of all variance in the plasma $\mathrm{Mg}^{2+}$ concentration.

Conclusions: Hypomagnesemia is highly prevalent in type 2 diabetes patients. Plasma triglycerides and glucose levels are major determinants of the plasma $\mathrm{Mg}^{2+}$ concentration, whereas only a minor part $(<10 \%)$ of hypomagnesemia can be explained by drug intake, excluding polypharmacy as a major cause for hypomagnesemia in type 2 diabetes.
\end{abstract}

\section{Introduction}

Over the last decades, evidence is accumulating that hypomagnesemia (plasma $\mathrm{Mg}^{2+}$ concentration $<0.7 \mathrm{mmol} / \mathrm{L}$ ) is frequently present in patients with type 2 diabetes (1). Since its first report in the 1940s, hypomagnesemia has been shown in several cohort studies $(2,3,4)$. Although plasma $\mathrm{Mg}^{2+}$ levels are not regularly monitored in type 2 diabetes patients, the presence of hypomagnesemia is of significant clinical importance (5). Oral $\mathrm{Mg}^{2+}$ supplementation has been shown to reduce the progression from pre-diabetes to diabetes and improves insulin sensitivity and glucose handling $(3,6,7,8)$.
Moreover, in type 2 diabetes patients, hypomagnesemia results in a faster renal decline and is associated with a worse disease progression and outcome $(9,10) . \mathrm{Mg}^{2+}$ also plays a key role in common comorbidities of type 2 diabetes such as chronic kidney disease, atherosclerosis and hypertension $(11,12,13,14)$.

Hypomagnesemia can have many underlying causes, related or unrelated to type 2 diabetes $(1,15)$. First, hypomagnesemia can result from mutations in magnesiotropic genes, which has been extensively reviewed by Viering et al. (16). Second, the processing of food leads to
() 2017 European Society of Endocrinology Printed in Great Britain
Published by Bioscientifica Ltd. 
a marked depletion of $\mathrm{Mg}^{2+}$ in the Western diet, resulting in a reduced dietary $\mathrm{Mg}^{2+}$ intake (17). Third, hypomagnesemia can be a result of impaired intestinal $\mathrm{Mg}^{2+}$ uptake due to diarrhea that could be induced by diabetic autonomic neuropathy or metformin use $(18,19,20)$. Fourth, the use of certain medication (i.e. diuretics, immunosuppressive drugs, proton pump inhibitors (PPIs)) has been associated with hypomagnesemia (21). Lastly, metabolic acidosis and insulin resistance can decrease the expression of the renal $\mathrm{Mg}^{2+}$ channel transient receptor potential melastatin 6 (TRPM6), increasing urinary $\mathrm{Mg}^{2+}$ loss and thereby reducing the plasma $\mathrm{Mg}^{2+}$ concentration $(22,23)$.

The origin of hypomagnesemia in type 2 diabetes is currently unknown. The contributing factors to disturbed $\mathrm{Mg}^{2+}$ homeostasis may be multiple and have been poorly studied. Type 2 diabetes patients suffer from a wide range of clinical disturbances including increased plasma glucose concentrations, dyslipidemia (high triglyceride and low HDL cholesterol) and insulin resistance (24).

To maintain proper glucose levels and blood pressure, polypharmacy is an inevitable consequence of effectively treating type 2 diabetes. However, it also constitutes a growing risk factor as each drug carries its own side effects and drug-drug interactions (25). Potentially, the use of medication can contribute to hypomagnesemia. Several regularly prescribed drugs in type 2 diabetes are known to reduce the plasma $\mathrm{Mg}^{2+}$ levels, including PPIs and thiazide diuretics $(26,27,28,29,30)$. However, it is unclear to what extent the hypomagnesemia in type 2 diabetes patients can be explained by the extensive use of medication.
In this study, we aimed to determine the prevalence of hypomagnesemia in a carefully phenotyped cohort of 402 type 2 diabetes patients. Subsequently, the determinants of plasma $\mathrm{Mg}^{2+}$ levels were analyzed using laboratory parameters and an extensive screening of drug use.

\section{Subjects and methods}

\section{Subjects}

Patients data and samples were taken from the Nijmegenpart of the Diabetes Pearl cohort (31). In short, 402 type 2 diabetes patients were included between June 2009 and February 2012 at the Radboud University Medical Center in Nijmegen, The Netherlands. Inclusion criteria were based on the WHO standards: a venous fasting plasma glucose concentration higher than $7.0 \mathrm{mmol} / \mathrm{L}$ or a casual venous plasma glucose concentration higher than $11.1 \mathrm{mmol} / \mathrm{L}$ (32). Personal information was obtained by dedicated patient questionnaires. This cohort consisted of patients under chronic secondary and tertiary care including many patients at an advanced disease stage.

Body mass index (BMI) was calculated as the weight in kilograms divided by square of the height in meters. Blood pressure and heart rate were measured in triplicate, and the average value was used in subsequent analyses. Waist circumference was measured in duplicate after normal exhalation and if the difference between these two measurements was $>1.0 \mathrm{~cm}$, the measurement was repeated for a third time. Plasma and urine samples were

Table 1 Characteristics of type 2 diabetes patients.

\begin{tabular}{l}
\hline Variable \\
\hline Demographics \\
Gender (m:f, \%) \\
BMI $\left(\mathrm{kg} / \mathrm{m}^{2}\right)$ \\
Age (years) \\
Duration diabetes (years) \\
Waist circumference $(\mathrm{m}: \mathrm{f}, \mathrm{cm})$ \\
SBP $(\mathrm{mmHg})$ \\
DBP (mmHg) \\
Heart rate (beats/min) \\
Alcohol consumption (no:yes, \%) \\
Laboratory analyses \\
Total cholesterol (mmol/L) \\
Triglycerides (mmol/L) \\
HbA1c (mmol/mol) \\
Glucose (mmol/L) \\
LDL (mmol/L) \\
HDL (m:f, mmol/L)
\end{tabular}

\begin{tabular}{c}
\hline Mean \pm s.D. \\
\\
$59: 41$ \\
$32.6 \pm 6.5$ \\
$67 \pm 10$ \\
$15.8 \pm 9.5$ \\
$110 \pm 16$ \\
$143 \pm 20$ \\
$77 \pm 11$ \\
$73 \pm 12$ \\
$52: 48$ \\
$4.5 \pm 1.5$ \\
$2.5 \pm 4.1$ \\
$63.1 \pm 14.2$ \\
$9.4 \pm 3.4$ \\
$2.3 \pm 0.8$ \\
$1.1 \pm 0.3$
\end{tabular}

\begin{tabular}{c}
\hline Range \\
\hline \\
$17-61$ \\
$34-90$ \\
$0-56$ \\
$65-152$ \\
$84-207$ \\
$51-117$ \\
$45-116$ \\
- \\
$2.0-20.0$ \\
$0.4-50.7$ \\
$33.3-118.6$ \\
$2.3-24.9$ \\
$0.6-4.9$ \\
$0.5-2.2$ \\
\hline
\end{tabular}

\begin{tabular}{c}
\hline Reference value \\
- \\
$18.5-25$ \\
- \\
- \\
$<102:<88$ \\
$90-140$ \\
$60-90$ \\
$60-100$ \\
- \\
$<5.2$ \\
$<1.7$ \\
$<42$ \\
$3.9-5.5$ \\
$<2.6$ \\
$>1.1:>1.3$
\end{tabular}

BMI, body mass index; DBP, diastolic blood pressure; f, female; HbA1c, glycated hemoglobin; HDL, high-density lipoprotein; LDL, low-density lipoprotein; m, male; SBP, systolic blood pressure. 
Table 2 Medication use of type 2 diabetes patients.

\begin{tabular}{|c|c|c|}
\hline Medication & $\begin{array}{c}\text { Number of } \\
\text { patients }(n=395)\end{array}$ & Percentage \\
\hline ACE inhibitor & 187 & 47.3 \\
\hline ANGIIR antagonist & 95 & 24.1 \\
\hline$\beta$-Adrenergic agonist & 31 & 7.8 \\
\hline$\beta$-Adrenergic antagonist & 209 & 52.9 \\
\hline Calcium channel blocker & 88 & 22.3 \\
\hline Insulin & 299 & 75.7 \\
\hline $\mathrm{K}^{+}$-saving diuretic & 48 & 12.2 \\
\hline Loop diuretic & 75 & 19.0 \\
\hline Metformin & 251 & 63.5 \\
\hline Nitrate & 54 & 13.7 \\
\hline PPI & 179 & 45.3 \\
\hline Statin & 293 & 74.2 \\
\hline Sulfonylureum & 77 & 19.5 \\
\hline Thiazide diuretic & 128 & 32.4 \\
\hline
\end{tabular}

$\mathrm{ACE}$, angiotensin-converting enzyme; ANGIIR, angiotensin II receptor; PPI, proton pump inhibitor.

taken after an overnight fasting period. The samples were analyzed for laboratory parameters (glycated hemoglobin (HbA1c), plasma glucose, creatinine, total cholesterol, high-density lipoprotein (HDL), low-density lipoprotein (LDL) and triglycerides) and immediately stored at $-80^{\circ} \mathrm{C}$ for further analyses. A detailed description of the patient characteristics is reported in Table 1.

Participants were requested to bring all their medication on the day of the visit or lists from pharmacists to score their medication use accurately. Medication was classed into groups according to the Anatomical Therapeutic Chemical Classification System (ATC) for statistical analysis (Table 2). The study was performed according to the Declaration of Helsinki. All patients provided written informed consent. All study investigators had access to the study data, and they reviewed and approved the final manuscript.

\section{Measures}

This study was designed as an observational cohort study using samples from the existing Diabetes Pearl cohort biobank (31). Laboratory values (fasting) and use of medication of 402 patients were examined at the inclusion date. Seven patients were excluded because of insufficient sample availability. Not only $\mathrm{Mg}^{2+}$ but also sodium $\left(\mathrm{Na}^{+}\right)$ and potassium $\left(\mathrm{K}^{+}\right)$concentrations were measured in the stored plasma and urine samples from the biobank. Fasting plasma $\mathrm{Mg}^{2+}$ concentrations were determined using a spectrophotometric assay (Roche/Hitachi) and measured at $600 \mathrm{~nm}$ on a Bio-Rad Benchmark plus microplate spectrophotometer (Bio-Rad Laboratories),

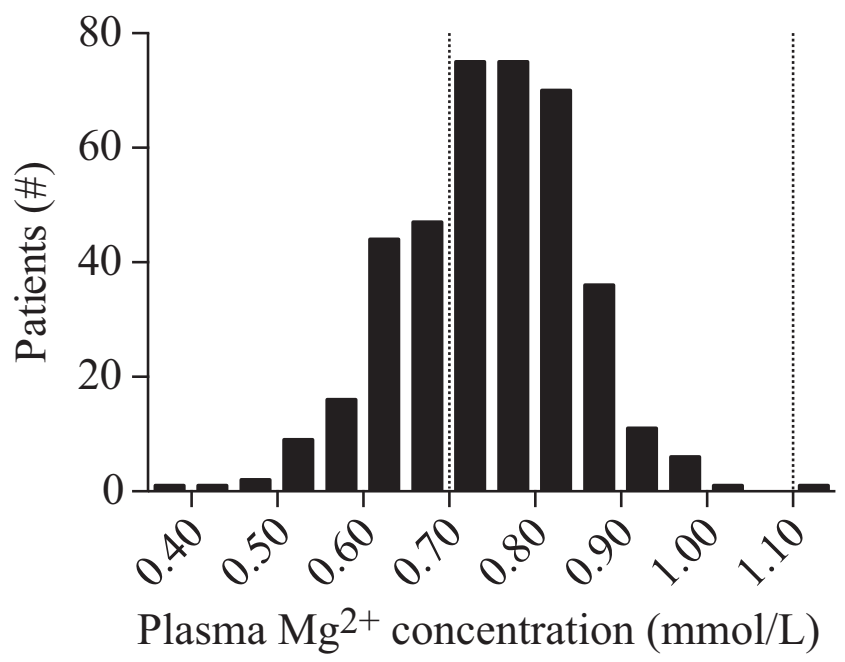

\section{Figure 1}

Hypomagnesemia in type 2 diabetes patients. The plasma $\mathrm{Mg}^{2+}$ concentration was determined in 395 type 2 diabetes patients. Hypomagnesemia was observed in $30.6 \%$ of the patients. Bars represent the number of patients. Dotted vertical lines indicate the normal range $(0.7-1.1 \mathrm{mmol} / \mathrm{L})$.

according to the manufacturer's protocol. Fasting plasma $\mathrm{Na}^{+}, \mathrm{K}^{+}$and creatinine and urinary $\mathrm{Mg}^{2+}, \mathrm{Na}^{+}, \mathrm{K}^{+}$and creatinine concentrations were measured at the clinical chemistry department using standardized methods. The fractional excretion of $\mathrm{Mg}^{2+}$ (FEMg) was calculated according to the formula $\left(U_{\mathrm{Mg}} \times S_{\text {crea }}\right) /\left(U_{\text {crea }} \times S_{\mathrm{Mg}}\right) \times 70$ (33). GFR was estimated (eGFR) using the 'Modification of Diet in Renal Disease' (MDRD) formula: $186 \times$ plasma creatinine $\mathrm{e}^{-1.154} \times$ age $^{-0.203} \times 1.210$ (if black) $\times 0.742$ (if female) (34). Patients with an eGFR $<30 \mathrm{~mL} / \mathrm{min}$ were excluded from subsequent urinary analyses.

\section{Statistical analysis}

Data are presented as mean \pm standard deviation (s.D.). Pearson's correlation tests were performed to determine the association between plasma $\mathrm{Mg}^{2+}$ concentration and clinical and anthropomorphic parameters. HbA1c and plasma values of triglycerides, glucose, LDL, HDL and total cholesterol were $\log _{10}$ transformed before use in statistical analyses. All variables with a $P$ value $<0.1$ in the Pearson's correlation analyses, not corrected for multiple testing, were checked for confounding by performing partial regression analyses. Variables that correlated to plasma $\mathrm{Mg}^{2+}$ concentration with $P<0.1$, after correcting for confounding, were included in the stepwise multivariate backward elimination model. In this model, variables 
Table 3 Univariate analyses for correlation of patient characteristics on plasma $\mathrm{Mg}^{2+}$ concentration.

\begin{tabular}{|c|c|c|c|}
\hline Variable & $\begin{array}{c}\text { Pearson's correlation } \\
\text { coefficient }\end{array}$ & $P$ value & $n$ \\
\hline \multicolumn{4}{|l|}{ Demographics } \\
\hline Gender & 0.007 & 0.897 & 395 \\
\hline BMI $\left(\mathrm{kg} / \mathrm{m}^{2}\right)$ & -0.162 & 0.001 & 394 \\
\hline Age (years) & 0.089 & 0.076 & 395 \\
\hline Duration diabetes (years) & 0.139 & 0.008 & 365 \\
\hline Waist circumference $(\mathrm{cm})$ & -0.158 & 0.002 & 392 \\
\hline $\mathrm{SBP}(\mathrm{mmHg})$ & -0.056 & 0.269 & 395 \\
\hline $\mathrm{DBP}(\mathrm{mmHg})$ & -0.144 & 0.004 & 395 \\
\hline Heart rate (beats/min) & -0.104 & 0.039 & 395 \\
\hline Alcohol consumption (no/yes) & -0.004 & 0.680 & 390 \\
\hline \multicolumn{4}{|l|}{ Laboratory analyses } \\
\hline eGFR (mL/min) & -0.168 & 0.001 & 371 \\
\hline $\log _{10} \mathrm{HDL}(\mathrm{mmol} / \mathrm{L})$ & 0.156 & 0.002 & 387 \\
\hline $\mathrm{Log}_{10}$ total cholesterol $(\mathrm{mmol} / \mathrm{L})$ & -0.059 & 0.247 & 388 \\
\hline $\log _{10} \mathrm{HbA} 1 \mathrm{c}(\mathrm{mmol} / \mathrm{mol})$ & -0.123 & 0.015 & 391 \\
\hline $\log _{10}$ triglycerides $(\mathrm{mmol} / \mathrm{L})$ & -0.273 & $<0.001$ & 387 \\
\hline $\log _{10}$ glucose $(\mathrm{mmol} / \mathrm{L})$ & -0.231 & $<0.001$ & 383 \\
\hline $\log _{10} \mathrm{LDL}(\mathrm{mmol} / \mathrm{L})$ & 0.077 & 0.145 & 365 \\
\hline Plasma $\mathrm{Na}^{+}(\mathrm{mmol} / \mathrm{L})$ & 0.108 & 0.032 & 391 \\
\hline Plasma K+ (mmol/L) & 0.081 & 0.110 & 394 \\
\hline \multicolumn{4}{|l|}{ Medication } \\
\hline ACE inhibitor & -0.094 & 0.063 & \\
\hline ANGIIR antagonist & 0.037 & 0.469 & \\
\hline$\beta$-Adrenergic agonist & -0.103 & 0.041 & \\
\hline$\beta$-Blocker & -0.056 & 0.270 & \\
\hline Calcium channel blocker & -0.072 & 0.155 & \\
\hline Insulin & 0.109 & 0.030 & \\
\hline $\mathrm{K}^{+}$-saving diuretic & -0.023 & 0.685 & \\
\hline Loop diuretic & 0.072 & 0.153 & \\
\hline Metformin & -0.268 & $<0.001$ & \\
\hline Nitrate & -0.043 & 0.389 & \\
\hline PPI & -0.084 & 0.094 & \\
\hline Statin & 0.002 & 0.962 & \\
\hline Sulfonylureum & -0.044 & 0.382 & \\
\hline Thiazide diuretic & -0.084 & 0.104 & \\
\hline
\end{tabular}

ACE, angiotensin-converting-enzyme; ANGIIR, angiotensin II receptor; BMI, body mass index; DBP, diastolic blood pressure; eGFR, estimated glomerular filtration rate; HbA1c, glycated hemoglobin; HDL, high-density lipoprotein; LDL, low density lipoprotein; PPI, proton pump inhibitor; SBP, systolic blood pressure.

with $P>0.1$ were eliminated. All statistical analyses were performed using SPSS for Windows (V22.0.0.1 IBM). A $P$ value of $<0.05$ was considered statistically significant.

\section{Results}

\section{Study population}

In total, 395 type 2 diabetes patients were included in the study cohort. Clinical characteristics and laboratory results are provided in Table 1. This is a group of patients with longstanding diabetes, mostly on insulin treatment with an extensive use of medication (Table 2). The average plasma $\mathrm{Mg}^{2+}$ concentration in the cohort was
$0.74 \pm 0.10 \mathrm{mmol} / \mathrm{L}$, and a total of 121 patients $(30.6 \%)$ had levels below $0.70 \mathrm{mmol} / \mathrm{L}$, indicating hypomagnesemia (Fig. 1). Hypermagnesemia was found in 1 patient. Plasma $\mathrm{Na}^{+}$and $\mathrm{K}^{+}$levels were normally distributed in the reference range (Supplementary Fig. 1, see section on supplementary data given at the end of this article).

\section{Determinants of the plasma $\mathrm{Mg}^{2+}$ concentration}

Using univariate regression analyses, a correlation between plasma $\mathrm{Mg}^{2+}$ concentration and several clinical characteristics was demonstrated: BMI $(r=-0.162$, $P=0.001)$, waist circumference $(r=-0.158, P=0.002)$, diastolic blood pressure (DBP, $r=-0.144, P=0.004$ ), 
Table 4 Stepwise backward regression analysis on plasma $\mathrm{Mg}^{2+}$ concentration.

\begin{tabular}{l} 
Variable \\
\hline $\log _{10}$ triglycerides (mmol/L) \\
$\log _{10}$ glucose $(\mathrm{mmol} / \mathrm{L})$ \\
eGFR (mL/min) \\
PPI* \\
Metformin* \\
Insulin* \\
$\beta$-Adrenergic agonist*
\end{tabular}

\begin{tabular}{c}
\hline Coefficient \\
\hline-0.073 \\
-0.149 \\
0.000 \\
-0.023 \\
-0.044 \\
0.023 \\
-0.047 \\
\hline
\end{tabular}

\begin{tabular}{r}
\hline $\boldsymbol{P}$ value \\
\hline$<0.001$ \\
$<0.001$ \\
0.022 \\
0.022 \\
$<0.001$ \\
0.053 \\
0.009
\end{tabular}

\begin{tabular}{c}
\hline Range \\
\hline-0.113 to -0.033 \\
-0.216 to -0.082 \\
-0.001 to 0.000 \\
-0.043 to -0.003 \\
-0.065 to -0.023 \\
$0.000-0.046$ \\
-0.082 to -0.012 \\
\hline
\end{tabular}

All variables with a $P>0.1$ were excluded from the model.

*No: 0, Yes: 1. eGFR, estimated glomerular filtration rate; PPI, proton pump inhibitor.

heart rate $(r=-0.104, P=0.039)$, eGFR $(r=-0.168$, $P=0.001)$, HbA1c $(r=-0.123, P=0.015)$ and plasma levels of triglycerides $(r=-0.273, P<0.001)$ and glucose $(r=-0.231, \quad P<0.001)$ negatively correlated with the plasma $\mathrm{Mg}^{2+}$ concentration. In contrast, the duration of diabetes $(r=0.139, P=0.008)$ and the plasma level of HDL $(r=0.156, P=0.002)$ and $\mathrm{Na}^{+}(r=0.108, P=0.032)$ were correlated with an increased plasma $\mathrm{Mg}^{2+}$ concentration (Table 3).

The effect of drug use was specifically analyzed. The use of metformin $(r=-0.268, P<0.001)$ or $\beta$-adrenergic receptor agonists $(r=-0.103, P=0.041)$ negatively correlated with plasma $\mathrm{Mg}^{2+}$, whereas use of insulin $(r=0.109, P=0.030)$ was associated with higher plasma $\mathrm{Mg}^{2+}$ levels.

Confounding factors were identified using partial correlation analyses and excluded from subsequent analysis (Supplementary Tables 1, 2, 3). After correction for confounding, all parameters correlating $(P<0.1)$ with plasma $\mathrm{Mg}^{2+}$ univariately, were included in the stepwise backward regression analysis model (Table 4). In this model, parameters with a $P$ value $>0.1$ were eliminated (BMI, DBP and angiotensin-converting enzyme (ACE) inhibitors). In the final model, plasma levels of glucose and triglycerides, as well as the use of PPIs, metformin or $\beta$-adrenergic receptor agonists negatively predicted plasma $\mathrm{Mg}^{2+}$ levels. Interestingly, patients on insulin had a trend $(P=0.053)$ toward having higher plasma $\mathrm{Mg}^{2+}$ levels than people not on insulin. Altogether, the model predicted $\left(R^{2}\right) 20 \%$ of the plasma $\mathrm{Mg}^{2+}$ concentration.

\section{Increased urinary $\mathrm{Mg}^{2+}$ excretion}

To investigate whether the hypomagnesemia is explained by renal $\mathrm{Mg}^{2+}$ loss, the fractional excretion of $\mathrm{Mg}^{2+}(\mathrm{FEMg})$ was determined. The mean FEMg in the cohort was $3.9 \pm 2.7 \%$. In total, 148 patients $(40.8 \%)$ suffered from renal $\mathrm{Mg}^{2+}$ wasting, defined as FEMg $>4 \%$. Nevertheless,
FEMg was not significantly different $(P=0.75)$ between normomagnesemic patients $(3.9 \pm 2.8 \%)$ and hypomagnesemic patients $(3.9 \pm 2.5 \%)$ (Fig. 2 ).
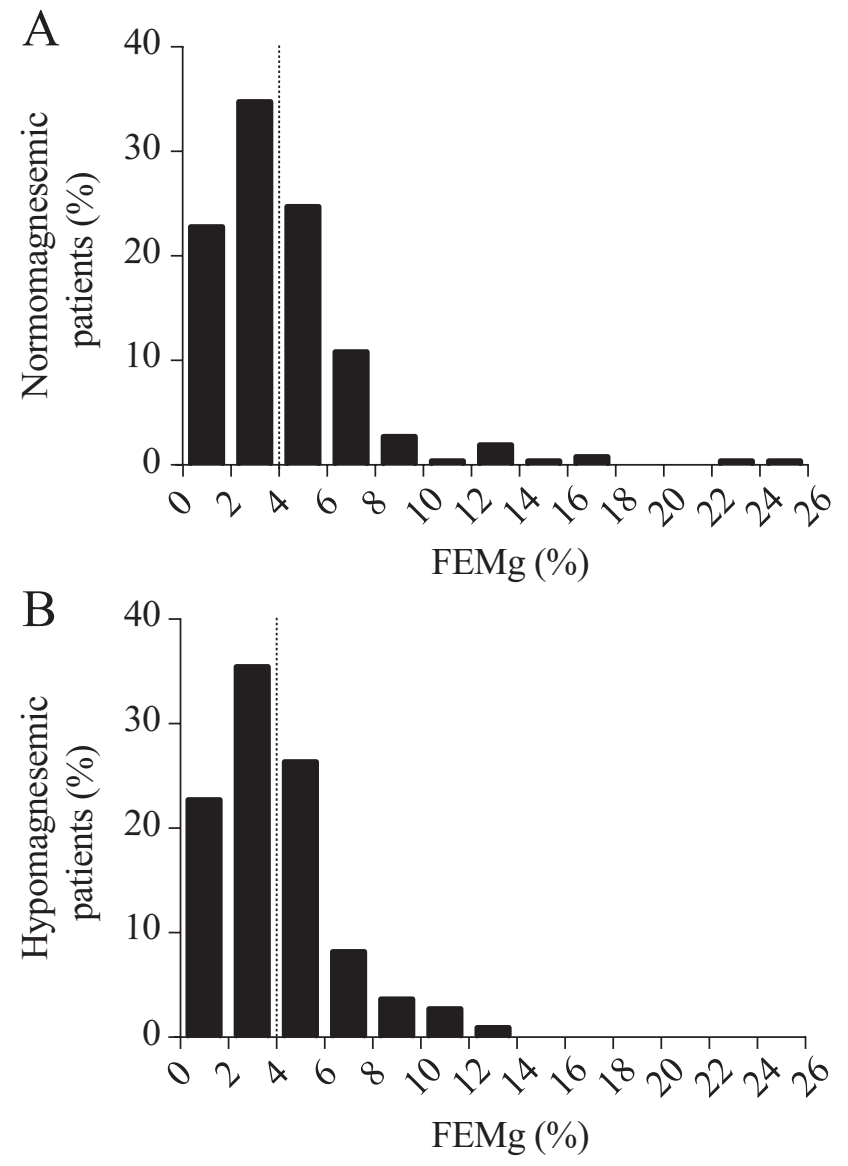

Figure 2

Increased FEMg in type 2 diabetes patients. The fractional excretion of $\mathrm{Mg}^{2+}$ (FEMg) was determined in 369 type 2 diabetes patients, of which 259 were normomagnesemic (A) and 110 were hypomagnesemic (B). Bars represent the percentage of the population. Dotted vertical lines indicate the threshold for urinary $\mathrm{Mg}^{2+}$ wasting (FEMg $>4 \%$ ). 


\section{Discussion}

This study further substantiates the high prevalence of hypomagnesemia in type 2 diabetes. A negative correlation between plasma $\mathrm{Mg}^{2+}$ concentration and the plasma glucose and triglycerides levels was demonstrated. In addition, polypharmacy could be excluded as the main cause of hypomagnesemia in type 2 diabetes patients as only less than ten percent of changes in plasma $\mathrm{Mg}^{2+}$ could be attributed to medication use. These findings suggest that hypomagnesemia in type 2 diabetes patients is intrinsic to the disease.

Hypomagnesemia was observed in $30.6 \%$ of the patients, corresponding to incidence numbers of 13.5$47.7 \%$ observed in previous cohort studies $(3,4,35,36)$. In comparison, in a large study of 5179 subjects aged 55 and older, the incidence of hypomagnesemia was only $2 \%$, highlighting the extensive amount of hypomagnesemia diabetes mellitus type 2 patients (10). Given that hypomagnesemia is related to a faster disease progression and an increased risk of diabetes-related complications, such as renal failure and cardiovascular disease, it is of great clinical importance to identify the factors that determine plasma $\mathrm{Mg}^{2+}$ concentrations $(1,9,13,37)$. Therefore, we constructed a statistical model that includes the factors influencing plasma $\mathrm{Mg}^{2+}$ levels. Twenty percent of the variation in plasma $\mathrm{Mg}^{2+}$ concentration is explained by our model containing eGFR, the plasma concentrations of glucose and triglycerides and the use of PPIs, insulin, metformin and $\beta$-adrenergic receptor agonists. Although this is only a modest part of the total variation, it is comparable to the effect of dietary $\mathrm{Mg}^{2+}$ intake and higher than current genetic models, which explain $25-30 \%$ and $1-5 \%$ of changes in the plasma $\mathrm{Mg}^{2+}$ concentration respectively $(38,39,40)$. The finding that in our model most of the variance in plasma $\mathrm{Mg}^{2+}$ can be explained by factors that determine metabolic control underlines the importance of glucose and lipid homeostasis in the regulation of plasma $\mathrm{Mg}^{2+}$ levels.

Plasma glucose and triglyceride levels were the main determinants of plasma $\mathrm{Mg}^{2+}$ concentrations in our model. This correlation was independent of obesityrelated factors such as waist circumference, BMI and cholesterol. Previous studies investigating metabolic syndrome have shown an association between triglycerides and $\mathrm{Mg}^{2+}$ levels $(41,42)$. However, these studies did not investigate the collinearity between triglycerides and HDL or were not based on the plasma $\mathrm{Mg}^{2+}$ concentration. $\mathrm{Mg}^{2+}$ supplementation is generally considered to improve the lipid profile in patients; however, studies addressing the effect of $\mathrm{Mg}^{2+}$ on plasma triglyceride concentrations are inconsistent $(43,44)$. As $\mathrm{Mg}^{2+}$ increases the affinity of the insulin receptor tyrosine kinase for ATP, the decreased plasma $\mathrm{Mg}^{2+}$ levels could exacerbate insulin resistance in type 2 diabetes patients, and thereby increase plasma glucose and triglyceride concentrations $(45,46)$.

Medication could only explain a minor part of the changes in plasma $\mathrm{Mg}^{2+}$ concentration in type 2 diabetes patients $(<10 \%)$, showing that polypharmacy is not the primary cause of hypomagnesemia in type 2 diabetes patients. Known hypomagnesemia-causing drugs, $\beta$-adrenergic receptor agonists and PPIs negatively correlated with the plasma $\mathrm{Mg}^{2+}$ concentration, although with minor effect sizes $(<2 \%)(30,47,48,49)$. Of all drugs, the use of metformin was most strongly correlated $(r=-0.268, P<0.001)$ with the plasma $\mathrm{Mg}^{2+}$ concentration, irrespective of eGFR or fasting glucose levels. Our study is the first large cohort study to identify the association between the use of metformin and plasma $\mathrm{Mg}^{2+}$ levels. A few studies with limited patient numbers from the 70s and 80s suggested that treating patients with metformin reduces plasma $\mathrm{Mg}^{2+}$ levels (4, 50). How metformin affects $\mathrm{Mg}^{2+}$ handling remains to be elucidated. In contrast, patients taking insulin had a trend $(P=0.053)$ toward higher plasma $\mathrm{Mg}^{2+}$ levels than those who did not require insulin treatment. This is in concordance with experimental studies showing that insulin stimulates the renal $\mathrm{Mg}^{2+}$ channel TRPM6, resulting in increased renal $\mathrm{Mg}^{2+}$ reabsorption (23). Therefore, despite their worse glycemic control, patients on insulin treatment have slightly better plasma $\mathrm{Mg}^{2+}$ values than metformin-treated patients. These results suggest that the positive renal effect of insulin on the reabsorption of $\mathrm{Mg}^{2+}$ overrides the negative effect of poor glycemic control of insulin-dependent patients on their $\mathrm{Mg}^{2+}$ levels.

We observed that high renal $\mathrm{Mg}^{2+}$ excretion is prevalent among type 2 diabetes patients, with $41 \%$ of the patients in the cohort having a FEMg $>4 \%$. Although these findings suggest that impaired renal $\mathrm{Mg}^{2+}$ reabsorption contributes to hypomagnesemia in type 2 diabetes patients, renal $\mathrm{Mg}^{2+}$ wasting was equally frequent in hypomagnesemic and normomagnesemic patients. Hypomagnesemia only arises when body $\mathrm{Mg}^{2+}$ stores, such as bone, are depleted (51). Therefore, hypomagnesemia may only develop after several years, despite increased renal $\mathrm{Mg}^{2+}$ excretion. Our findings of overall high $\mathrm{Mg}^{2+}$ excretion may thus indicate that the complete diabetic population is at risk to develop hypomagnesemia. FEMg was not related to fasting glucose 
levels (data not shown), showing that diabetes severity does not influence the amount of urinary $\mathrm{Mg}^{2+}$ loss.

The strength of our study is the thorough and extensive phenotyping of the diabetes patients, allowing systematic investigation of the contribution of polypharmacy and metabolism-related parameters to changes in the plasma $\mathrm{Mg}^{2+}$ concentration of type 2 diabetes patients. By carefully collecting data on drug use, this is the first cohort study that determined the contribution of medication usage to changes in plasma $\mathrm{Mg}^{2+}$ concentrations. The availability of urine samples enabled the determination of the FEMg in a large cohort of severe type 2 diabetes patients for the first time.

However, several limitations have to be considered. First, data on the dietary habits of the participants was not collected, excluding the potential effects of diet from our analyses. However, the influence of diet on plasma $\mathrm{Mg}^{2+}$ levels will be minor, as samples were collected after an overnight fast. Secondly, all the samples were collected at a single point, and no follow-up data are available. Therefore, the observed correlations will not provide information about causality. A final limitation is the fact that the extent of insulin resistance was not directly determined. However, several studies have proposed that the product of fasting glucose and triglycerides can be used as a measure to estimate insulin resistance $(52,53)$. The strong correlation of plasma $\mathrm{Mg}^{2+}$ with glucose and triglycerides in our study therefore provides an indirect link with insulin resistance.

In conclusion, this study shows that hypomagnesemia is a prominent feature of type 2 diabetes, and is supported by excessive urinary $\mathrm{Mg}^{2+}$ loss. We excluded polypharmacy as the major cause of changes in plasma $\mathrm{Mg}^{2+}$ concentration in type 2 diabetes patients. Given that metabolic factors such as glucose and triglyceride concentrations are main determinants of the plasma $\mathrm{Mg}^{2+}$ concentration, $\mathrm{Mg}^{2+}$ disturbances should be considered and, if required, corrected in type 2 diabetes patients.

\section{Supplementary data}

This is linked to the online version of the paper at http://dx.doi.org/10.1530/ EJE-16-0517.

\section{Declaration of interest}

The authors declare that there is no conflict of interest that could be perceived as prejudicing the impartiality of the research reported.

\section{Funding}

This study was supported by funding from the Radboud Institute for Molecular Life Science and by grants from the Netherlands Organization for Scientific Research (NWO VICI 016.130.668) and the EURenOmics project from the European Union seventh Framework Programme (FP7/2007-2013, agreement no. 305608) to J H. J H F B is supported by grants from NWO (Rubicon 825.14.021) and the Dutch Kidney Foundation (Kolff grant 14OKG17).

\section{Author contribution statement}

Data were collected by $\mathrm{S} \mathrm{K}$ and $\mathrm{H}$ B. Statistical analysis was done by $\mathrm{S} K$. Manuscript was written by S K, J B, R B, C T and J H, and it was supervised by $J$ B, R B, C T and J H. All authors have read and approved the final version of the manuscript. $\mathrm{J} \mathrm{H}$ is the guarantor of this work and, as such, had full access to all the data in the study and takes responsibility for the integrity of the data and the accuracy of the data analysis.

\section{Acknowledgements}

The authors are greatly indebted to all the patients of the Diabetes Pearl cohort and like to thank Dick Thijssen and Martijn Maessen (Department of Physiology, Radboudumc Nijmegen), and Jan van den Brand (Department of Nephrology, Radboudumc Nijmegen) for their insights in the statistical analyses. Marlies Fennis (Department of Physiology, Radboudumc Nijmegen), Anja Rasing-Hoogveld, Evertine Abbink (Clinical Research Centre, Radboudumc Nijmegen) and Rob Verheyen (Department of Theoretical High Energy Physics, Radboud University Nijmegen) for their excellent technical support.

\section{References}

1 Gommers LM, Hoenderop JG, Bindels RJ \& de Baaij JH. Hypomagnesemia in type 2 diabetes: a vicious circle? Diabetes 2016 65 3-13. (doi:10.2337/db15-1028)

2 Martin HE \& Wertman M. Serum potassium, magnesium, and calcium levels in diabetic acidosis. Journal of Clinical Investigation 194726 217-228. (doi:10.1172/JCI101799)

3 Pham PC, Pham PM, Pham SV, Miller JM \& Pham PT. Hypomagnesemia in patients with type 2 diabetes. Clinical Journal of the American Society of Nephrology 20072 366-373. (doi:10.2215/ CJN.02960906)

4 Mather HM, Nisbet JA, Burton GH, Poston GJ, Bland JM, Bailey PA \& Pilkington TR. Hypomagnesaemia in diabetes. Clinica Chimica Acta 197995 235-242. (doi:10.1016/0009-8981(79)90364-4)

5 Grober U, Schmidt J \& Kisters K. Magnesium in prevention and therapy. Nutrients 20157 8199-8226. (doi:10.3390/nu7095388)

6 Guerrero-Romero F, Tamez-Perez HE, Gonzalez-Gonzalez G, SalinasMartinez AM, Montes-Villarreal J, Trevino-Ortiz JH \& RodriguezMoran M. Oral magnesium supplementation improves insulin sensitivity in non-diabetic subjects with insulin resistance. A doubleblind placebo-controlled randomized trial. Diabetes and Metabolism 200430 253-258. (doi:10.1016/S1262-3636(07)70116-7)

7 Paolisso G, Sgambato S, Gambardella A, Pizza G, Tesauro P, Varricchio M \& D'Onofrio F. Daily magnesium supplements improve glucose handling in elderly subjects. American Journal of Clinical Nutrition 199255 1161-1167.

8 Hruby A, Meigs JB, O’Donnell CJ, Jacques PF \& McKeown NM. Higher magnesium intake reduces risk of impaired glucose and insulin metabolism and progression from prediabetes to diabetes in middle-aged americans. Diabetes Care 201437 419-427. (doi:10.2337/dc13-1397)

9 Pham PC, Pham PM, Pham PA, Pham SV, Pham HV, Miller JM, Yanagawa N \& Pham PT. Lower serum magnesium levels are associated with more rapid decline of renal function in patients with diabetes mellitus type 2. Clinical Nephrology 200563 429-436. (doi:10.5414/CNP63429)

10 Liamis G, Rodenburg EM, Hofman A, Zietse R, Stricker BH \& Hoorn EJ. Electrolyte disorders in community subjects: prevalence 
and risk factors. American Journal of Medicine 2013126 256-263. (doi:10.1016/j.amjmed.2012.06.037)

11 Peacock JM, Folsom AR, Arnett DK, Eckfeldt JH \& Szklo M. Relationship of serum and dietary magnesium to incident hypertension: the Atherosclerosis Risk in Communities (ARIC) Study. Annals of Epidemiology 19999 159-165. (doi:10.1016/S10472797(98)00040-4)

12 Ma J, Folsom AR, Melnick SL, Eckfeldt JH, Sharrett AR, Nabulsi AA, Hutchinson RG \& Metcalf PA. Associations of serum and dietary magnesium with cardiovascular disease, hypertension, diabetes, insulin, and carotid arterial wall thickness: the ARIC study. Atherosclerosis Risk in Communities Study. Journal of Clinical Epidemiology 199548 927-940. (doi:10.1016/0895-4356(94)00200-A)

13 de Roij van Zuijdewijn CL, Grooteman MP, Bots ML, Blankestijn PJ, Steppan S, Buchel J, Groenwold RH, Brandenburg V, van den Dorpel MA, Ter Wee PM et al. Serum magnesium and sudden death in European hemodialysis patients. PLOS ONE 201510 e0143104. (doi:10.1371/journal.pone.0143104)

14 Massy ZA \& Drueke TB. Magnesium and outcomes in patients with chronic kidney disease: focus on vascular calcification, atherosclerosis and survival. Clinical Kidney Journal 20125 i52-i61. (doi:10.1093/ ndtplus/sfr167)

15 Liamis G, Liberopoulos E, Barkas F \& Elisaf M. Diabetes mellitus and electrolyte disorders. World Journal of Clinical Cases 20142 488-496. (doi:10.12998/wjcc.v2.i10.488)

16 Viering DH, de Baaij JH, Walsh SB, Kleta R \& Bockenhauer D. Genetic causes of hypomagnesemia, a clinical overview. Pediatric Nephrology 2016. In press. (doi:10.1007/s00467-016-3416-3)

17 Marier JR. Magnesium content of the food supply in the modern-day world. Magnesium 19865 1-8.

18 Foss MT \& Clement KD. Metformin as a cause of late-onset chronic diarrhea. Pharmacotherapy 200121 1422-1424. (doi:10.1592/ phco.21.17.1422.34430)

19 Svare A. A patient presenting with symptomatic hypomagnesemia caused by metformin-induced diarrhoea: a case report. Cases Journal 20092 156. (doi:10.1186/1757-1626-2-156)

20 Vinik AI, Maser RE, Mitchell BD \& Freeman R. Diabetic autonomic neuropathy. Diabetes Care 200326 1553-1579. (doi:10.2337/ diacare.26.5.1553)

21 Lameris AL, Monnens LA, Bindels RJ \& Hoenderop JG. Drug-induced alterations in Mg2+ homoeostasis. Clinical Science 2012123 1-14. (doi:10.1042/CS20120045)

22 Nijenhuis T, Renkema KY, Hoenderop JG \& Bindels RJ. Acid-base status determines the renal expression of $\mathrm{Ca} 2+$ and $\mathrm{Mg} 2+$ transport proteins. Journal of the American Society of Nephrology $2006 \mathbf{1 7}$ 617-626. (doi:10.1681/ASN.2005070732)

23 Nair AV, Hocher B, Verkaart S, van Zeeland F, Pfab T, Slowinski T, Chen YP, Schlingmann KP, Schaller A, Gallati S et al. Loss of insulin-induced activation of TRPM6 magnesium channels results in impaired glucose tolerance during pregnancy. PNAS 2012109 11324-11329. (doi:10.1073/pnas.1113811109)

24 Wilcox G. Insulin and insulin resistance. Clinical Biochemist Reviews 200526 19-39.

25 Nyenwe EA, Jerkins TW, Umpierrez GE \& Kitabchi AE. Management of type 2 diabetes: evolving strategies for the treatment of patients with type 2 diabetes. Metabolism 201160 1-23. (doi:10.1016/j. metabol.2010.09.010)

26 DeFronzo RA, Cooke CR, Andres R, Faloona GR \& Davis PJ. The effect of insulin on renal handling of sodium, potassium, calcium, and phosphate in man. Journal of Clinical Investigation 197555 845-855. (doi:10.1172/JCI107996)

27 Nijenhuis T, Vallon V, van der Kemp AW, Loffing J, Hoenderop JG \& Bindels RJ. Enhanced passive Ca2+ reabsorption and reduced Mg2+ channel abundance explains thiazide-induced hypocalciuria and hypomagnesemia. Journal of Clinical Investigation $2005 \mathbf{1 1 5}$ 1651-1658. (doi:10.1172/JCI24134)
28 Martin BJ \& Milligan K. Diuretic-associated hypomagnesemia in the elderly. Archives of Internal Medicine 1987147 1768-1771. (doi:10.1001/archinte.1987.00370100082014)

29 Cohen N, Almoznino-Sarafian D, Zaidenstein R, Alon I, Gorelik O, Shteinshnaider M, Chachashvily S, Averbukh Z, Golik A, Chen-Levy Z $\&$ Modai D. Serum magnesium aberrations in furosemide (frusemide) treated patients with congestive heart failure: pathophysiological correlates and prognostic evaluation. Heart 200389 411-416. (doi:10.1136/heart.89.4.411)

30 Hess MW, Hoenderop JG, Bindels RJ \& Drenth JP. Systematic review: hypomagnesaemia induced by proton pump inhibition. Alimentary Pharmacology and Therapeutics 201236 405-413. (doi:10.1111/j.13652036.2012.05201.x)

31 van't Riet E, Schram MT, Abbink EJ, Admiraal WM, Dijk-Schaap MW, Holleman F, Nijpels G, Ozcan B, Pijl H, Schaper NC et al. The diabetes pearl: diabetes biobanking in The Netherlands. BMC Public Health 201212 949. (doi:10.1186/1471-2458-12-949)

32 Organization WH. Definition and Diagnosis of Diabetes Mellitus and Intermediate Hyperglycemia: Report of a WHO/IDF Consultation. Geneva, Switzerland: World Health Org, 2006.

33 Ayuk J \& Gittoes NJ. Contemporary view of the clinical relevance of magnesium homeostasis. Annals of Clinical Biochemistry $2014 \mathbf{5 1}$ 179-188. (doi:10.1177/0004563213517628)

34 National Kidney Foundation. K/DOQI clinical practice guidelines for chronic kidney disease: evaluation, classification, and stratification. American Journal of Kidney Diseases 200239 S1-S266.

35 de Lordes Lima M, Cruz T, Pousada JC, Rodrigues LE, Barbosa K \& Cangucu V. The effect of magnesium supplementation in increasing doses on the control of type 2 diabetes. Diabetes Care 199821 682-686. (doi:10.2337/diacare.21.5.682)

36 McNair P, Christensen MS, Christiansen C, Madsbad S \& Transbol I. Renal hypomagnesaemia in human diabetes mellitus: its relation to glucose homeostasis. European Journal of Clinical Investigation 198212 81-85. (doi:10.1111/j.1365-2362.1982.tb00942.x)

37 Bo S \& Pisu E. Role of dietary magnesium in cardiovascular disease prevention, insulin sensitivity and diabetes. Current Opinion in Lipidology 200819 50-56. (doi:10.1097/MOL.0b013e3282f33ccc)

38 Tin A, Kottgen A, Folsom AR, Maruthur NM, Tajuddin SM, Nalls MA, Evans MK, Zonderman AB, Friedrich CA, Boerwinkle E et al. Genetic loci for serum magnesium among African-Americans and gene-environment interaction at MUC1 and TRPM6 in EuropeanAmericans: the Atherosclerosis Risk in Communities (ARIC) study. BMC Genetics 201516 56. (doi:10.1186/s12863-015-0219-7)

39 Meyer TE, Verwoert GC, Hwang SJ, Glazer NL, Smith AV, van Rooij FJ, Ehret GB, Boerwinkle E, Felix JF, Leak TS et al. Genome-wide association studies of serum magnesium, potassium, and sodium concentrations identify six Loci influencing serum magnesium levels. PLoS Genetics 2010 6. (doi:10.1371/journal.pgen.1001045)

40 Akizawa Y, Koizumi S, Itokawa Y, Ojima T, Nakamura Y, Tamura T $\&$ Kusaka Y. Daily magnesium intake and serum magnesium concentration among Japanese people. Journal of Epidemiology 2008 18 151-159. (doi:10.2188/jea.JE2007381)

41 Corica F, Corsonello A, Ientile R, Cucinotta D, Di Benedetto A, Perticone F, Dominguez LJ \& Barbagallo M. Serum ionized magnesium levels in relation to metabolic syndrome in type 2 diabetic patients. Journal of the American College of Nutrition 200625 210-215. (doi:10.1080/07315724.2006.10719534)

42 Guerrero-Romero F \& Rodriguez-Moran M. Low serum magnesium levels and metabolic syndrome. Acta Diabetologica 200239 209-213. (doi:10.1007/s005920200036)

43 Lal J, Vasudev K, Kela AK \& Jain SK. Effect of oral magnesium supplementation on the lipid profile and blood glucose of patients with type 2 diabetes mellitus. Journal of the Association of Physicians of India $2003 \mathbf{5 1} 37-42$.

44 Song Y, He K, Levitan EB, Manson JE \& Liu S. Effects of oral magnesium supplementation on glycaemic control in Type 2 
diabetes: a meta-analysis of randomized double-blind controlled trials. Diabetic Medicine 200623 1050-1056. (doi:10.1111/j.14645491.2006.01852.x)

45 Vinals F, Camps M, Testar X, Palacin M \& Zorzano A. Effect of cations on the tyrosine kinase activity of the insulin receptor: inhibition by fluoride is magnesium dependent. Molecular and Cellular Biochemistry 1997171 69-73. (doi:10.1023/A:1006836001489)

46 Vicario PP \& Bennun A. Separate effects of Mg2+, MgATP, and ATP4- on the kinetic mechanism for insulin receptor tyrosine kinase. Archives of Biochemistry and Biophysics 1990278 99-105. (doi:10.1016/0003-9861(90)90236-R)

47 Cheungpasitporn W, Thongprayoon C, Kittanamongkolchai W, Srivali N, Edmonds PJ, Ungprasert P, O'Corragain OA, Korpaisarn S $\&$ Erickson SB. Proton pump inhibitors linked to hypomagnesemia: a systematic review and meta-analysis of observational studies. Renal Failure 201537 1237-1241. (doi:10.3109/08860 22X.2015.1057800)

48 Fagan TE \& Romani A. Activation of $\mathrm{Na}(+)$ - and $\mathrm{Ca}(2+)$-dependent $\mathrm{Mg}(2+)$ extrusion by alpha(1)- and beta-adrenergic agonists in rat liver cells. American Journal of Physiology: Gastrointestinal and Liver Physiology 2000279 G943-G950.
49 Lipworth BJ, McDevitt DG \& Struthers AD. Prior treatment with diuretic augments the hypokalemic and electrocardiographic effects of inhaled albuterol. American Journal of Medicine 198986 653-657. (doi:10.1016/0002-9343(89)90438-5)

50 McBain AM, Brown IR, Menzies DG \& Campbell IW. Effects of improved glycaemic control on calcium and magnesium homeostasis in type II diabetes. Journal of Clinical Pathology 198841 933-935. (doi:10.1136/jcp.41.9.933)

51 Swaminathan R. Magnesium metabolism and its disorders. Clinical Biochemist Reviews 200324 47-66.

52 Simental-Mendia LE, Rodriguez-Moran M \& Guerrero-Romero F. The product of fasting glucose and triglycerides as surrogate for identifying insulin resistance in apparently healthy subjects. Metabolic Syndrome and Related Disorders 20086 299-304. (doi:10.1089/met.2008.0034)

53 Guerrero-Romero F, Simental-Mendia LE, Gonzalez-Ortiz M, Martinez-Abundis E, Ramos-Zavala MG, Hernandez-Gonzalez SO, Jacques-Camarena O \& Rodriguez-Moran M. The product of triglycerides and glucose, a simple measure of insulin sensitivity. Comparison with the euglycemic-hyperinsulinemic clamp. Journal of Clinical Endocrinology and Metabolism 201095 3347-3351. (doi:10.1210/jc.2010-0288)

Received 16 June 2016

Revised version received 13 September 2016

Accepted 4 October 2016 